\title{
EEN SURINAAMS RECHTSGEDING OVER EEN MOSLIMSE VERSTOTING
}

Sinds in 1940 in Suriname de 'Aziatische' huwelijkswetgeving 1 tot stand kwam, is het voor Moslimse en Hindoese Surinamers mogelijk volgens hun eigen godsdienstige gebruiken een wettig huwelijk te sluiten, mits aan bepaalde voorwaarden (o.a. inschrijving) wordt voldaan. De gelegenheid om volgens de regels van het burgerlijk wetboek te trouwen, bleef evenwel voor deze bevolkingsgroepen bestaan. Dat de mogelijkheid van keuze tot complicaties aanleiding kan geven, kan geïllustreerd worden door een proces uit de jaren vijftig over de geldigheid van een verstoting, waarin het Paramaribo'se Hof van Justitie op I juni 1956 eindvonnis heeft gewezen.

Het betreft een zaak tussen William A. en zijn gewezen echtgenote Djamiran O., beiden Islamieten van Hindostaanse afstamming. ${ }^{2}$ Hun huwelijk was destijds gesloten op de voet van het 'huwelijksbesluit Mohammedanen' en dus naar de terminologie van dit besluit "een huwelijk volgens de leer van den Islam".

De man had, naar hij beweerde, zijn vrouw verstoten en wilde later met een ander huwen. Toen de vrouw dit voornemen vernam, heeft zij bij deurwaarders-exploit zich tegen de voltrekking van het tweede huwelijk verzet, m.a.w. het huwelijk gestuit. (Zie artikel 35 van het Surinaams burgerlijk wetboek.)

Om de stuiting opgeheven te krijgen bond de man, die natuurlijk langdurig uitstel van de huwelijksvoltrekking wilde vermijden, een 'kort

1 Besluiten van I4 oktober 1940, houdende bepalingen betreffende huwelijken van de den Islam (resp. het Hindoeïsme) belijdende immigranten en met hen gelijk gestelden in Suriname. G.B. I940. nos. I49 en I50. De naam 'Aziatische huwelijkswetgeving' is, hoewel in de praktijk bruikbaar, in feite niet juist; ze betreft immers alleen Hindoe's en Islamieten. Een niet-onbelangrijke Aziatische groep als die der Chinezen valt er geheel buiten, evenals alle Aziatische Christenen. Ook wat zijn inhoud betreft, vertoont dit stuk wetgeving enkele trekken, die bepaald niet Aziatisch te noemen zijn.

2 Het feit, dat de man een Christelijke, althans westerse, althans Engelse voornaam droeg, doet daaraan niets af; het gebruik van zulke voornamen neemt voor beide seksen, zowel onder Moslimse als onder Hindoese Surinamers van Voorindische afstamming, toe. Ook bij de Javanen komt het voeren van Europese voornamen - sinds de burgerlijke stand een familienaam eist - snel op. 
geding' aan. De kantonrechter verklaarde zich echter onbevoegd de zaak in kort geding te behandelen, omdat volgens artikel 676 van het Surinaams wetboek van burgerlijke rechtsvordering een eis tot opheffing van een stuiting in een normale procedure moet worden behandeld. Bovendien, artikel I 23 van het Surinaams burgerlijk wetboek verbiedt, dat, na stuiting van een huwelijk, de ambtenaar van de burgerlijke stand dit voltrekt, tenzij "aan hem zal zijn terhandgesteld een vonnis in kracht van gewijsde gegaan", dus een einduitspraak waarvan geen hoger beroep meer mogelijk is. Daarmee kan, volgens de kantonrechter, geen uitspraak in kort geding zijn bedoeld. Dit is de (voor ons doel overigens niet relevante) procesrechtelijke kant van de zaak en het standpunt van deze rechter lijkt onontkoombaar logisch.

De zaak werd dus opnieuw, nu als een gewoon proces, aanhangig gemaakt. ${ }^{1}$ Belangwekkend is in dit geval, dat de man ter terechtzitting verklaarde, zijn tweede huwelijk volgens de regels van de burgerlijke stand te willen sluiten en niet volgens het 'huwelijksbesluit Mohammedanen'. En voorts, dat de vrouw de verstoting ontkende en daarbij een interpretatie van de 'leer van den Islam' op dit punt in modern-reformistische zin gaf.

Zij voerde voor de rechter aan, dat de Korān (in hoofdstuk 64, deel 28) het volgende voorschrijft: "Als ge scheidt van Uw vrouw, scheid dan van haar voor een bepaalde periode (tenminste drie maanden) en verdrijf haar niet uit de echtelijke woning, behalve wanneer zij zich openlijk onbetamelijk gedraagt; als zij haar fout erkent, moet gij haar terug nemen; indien zij weigert, scheid van Uw echtgenote in het bijzijn van twee rechtvaardigen (getuigen) en Uw echtgenote..." Derhalve, zo werd van de zijde der vrouw betoogd, kan volgens de leer van de Islam verstoting door de man alleen plaats vinden met medewerking van de echtgenote, indien de echtgenote althans geen feiten heeft gepleegd, die grond opleveren voor verstoting. Heeft zij zulke feiten niet begaan, dan kan verstoting alleen plaats hebben met haar toestemming en in haar tegenwoordigheid.

Uit welke Korān-vertaling hier geciteerd werd, heb ik niet kunnen uitvinden. Het is in elk geval niet die van Soedewo, die voor de oorlog in Ned. Indië werd gepubliceerd. In de gezaghebbende Nederlandse vertaling van wijlen professor Kramers ${ }^{2}$ luidt de passage aldus: "(I) O gij profeet, wanneer gijlieden de vrouwen verstoot, zo verstoot haar met inachtneming van haar dagental, en telt het dagental. En vreest Allah uw Heer. Drijft haar niet uit haar huizen, maar niet zullen zij uittrekken dan ingeval zij klaarblijkende zedeloosheid bedrijven. En dat zijn de be-

1 Algemeen Register 1955 no. 2298.

2 De Koran, uit het Arabisch vertaald door J. H. Kramers (in leven hoogleraar in het Arabisch en de instellingen van de Islam te Leiden), Amsterdam-Brussel, 1956, p. 557. Vijf-en-zestigste Sūra, Al-talāk (De verstoting). - Met de zo juist in de tekst genoemde 'vertaling van Soedewo' wordt bedoeld 'De Heilige Qur'an, vervattende den Arabischen tekst met ophelderende aanteekeningen en voorrede van MAULvi MoEhammad Ali, M. A., LL.B., voorzitter Ahmadija Andjoeman-i-isja'at, Lahore, Voor-Indië, in het Nederlands vertaald door SoEdEwo, eerste druk, uitgegeven door Het Hoofdcomité Qoer'an-fonds onder de auspi- 
palingen Allah's. En wie de bepalingen Allah's overtreedt, die doet onrecht aan zichzelf. Niet weet gij of Allah daarna nog een nieuwe beschikking zal geven. (2) Wanneer zij dan het einde van haar termijn bereikt hebben [volgens Kramers is hier bedoeld: vier maanden], houdt haar dan terug naar het behoorlijke of scheidt $u$ van haar naar het behoorlijke. En neemt tot getuigen rechtschapen lieden onder $\mathrm{u}$, en geeft rechte getuigenis voor Allah. Dat is het waartoe vermaand worden wie geloven in Allah en de laatste Dag. En wie Allah vreest, voor hem bereidt Allah een uitweg".

Het standpunt, dat namens de vrouw voor de rechtbank verdedigd werd lijkt, op het eerste gezicht althans, in één opzicht 'Hanafietisch'. Volgens Wensinck \& Kramers immers is het bij de Hanafieten den man verboden (haram) zijn vrouw te verstoten zonder grond (unbegründete Vornahme). 1

De tegenpartij stelde in de loop van dit geding, dat de vrouw aanhangster was van Ahmadijah. ${ }^{2}$ En inderdaad kunnen wij in het standpunt van de vrouw in het hier besproken proces invloed van moderne Islamietische inzichten terugvinden, met name die van Maulana Muhammad 'Ali, de Voorindische geleerde, wiens grote boek over de leer van de Islam, in Nederlandse versie, in $193^{8}$ het licht heeft gezien. ${ }^{3}$

Deze Nederlandse editie van de Javaanse publicist Soedewo is in Suriname, als gevolg van de invloed der Ahmadijah-beweging aldaar, niet onbekend. De schrijver stelt zich op het standpunt, bij zijn bespreking van het begrip 'talāq', "dat er niet alleen een goede grond moet zijn voor huwelijksontbinding, maar ook dat alle middelen in het werk moeten zijn gesteld om verzoening teweeg te brengen, voor en aleer men tot dien uitersten maatregel zijn toevlucht neemt. Het idee, dat een Moslim zijn vrouw geheel naar willekeur zou kunnen verstooten, is een grove verdraaiing van de Islāmietische instelling der huwelijksontbinding" ${ }^{4} \mathrm{Hij}$ wijkt dus scherp af van het traditionele inzicht, volgens hetwelk de verstoting een rechtsmiddel is, dat de man geheel naar eigen willekeur zou kunnen hanteren, zonder aan enige instantie op aarde verantwoording schuldig te zijn.

ciën van De Ahmadijah-beweging Indonesia (Centrum-Lahore) 1934". Deze uitgave is buiten het voormalige Nederlands-Indië weinig verspreid en blijkbaar in Suriname niet bekend. - Uiteraard is voor schrijver dezes alleen van belang, welke invloeden hier werken.

1 Handwörterbuch des Islam, herausgegeben von A. J. WENSINCK und J. H. Kramers, Leiden, I94I, s.v. talāk, p. 7I9, kolom 2.

2 De Ahmadiyyah-beweging is in Nederland bekend, omdat zij daar zending bedrijft. [De in Nederland gevestigde Ahmadiyyah ressorteert onder de Kadiāngroep (de beweging is in twee groepen gesplitst: 'Lahore' en 'Kadian', thans Rabwah).] In 1953 is onder de auspiciën dezer beweging De Heilige Qor'aan met Nederlandse vertaling verschenen, waaraan Nederlanders hebben medegewerkt. (The Oriental and Religious Publishing Corporation, Rabwah-Punjab-Pakistan, 1953). Het was echter niet uit deze vertaling, dat de partij der vrouw heeft geciteerd.

3 De Religie van den Islam, een breedvoerige verhandeling van de bronnen, beginselen, wetten en voorschriften van den Islăm, door Maulana Muhammad 'Ali, in het Nederlandsch vertaald door Soedewo, uitgegeven door: Ahmadijah Beweging Indonesia (Centr. Lahore), 1938.

4 Maulana Muhammad 'Alí, p. 476. 
Geheel in de lijn van dit reformistische standpunt heeft de vrouw voor de rechter betoogd, dat er geen feiten waren, door haar als echtgenote begaan "welke een verstoting rechtens toelieten". Maar bovendien, zo meende zij, heeft de verstoting, anders dan haar (gewezen) echtgenoot zich verbeeldde "niet plaats gevonden op de wijze, en met inachtneming van de termijnen, zoals die door de leer van den Islam is voorgeschreven". Want "de echtgenoot, die zijn echtgenote verstoot, behoort haar mede te delen, op welke gronden hij wenst te verstoten". Als er "althans feiten aanwezig zijn, door de echtgenote gepleegd, die grond opleveren tot verstoting", dient de (schuldige) echtgenote in de gelegenheid te worden gesteld "om haar fout te verbeteren". Daartoe dienen de partijen zich te verzoenen, waardoor "de verstoting geen voortgang kan vinden". Dat alles is niet gebeurd; er heeft dus, zo concludeert zij, geen verstoting volgens de leer van de Islam plaatsgehad. Deze verstoting is "mitsdien nietig, moet als nietig worden beschouwd, behoort althans vernietigd te worden". (Aldus de voor de rechter gebruikte alternatieve formule.)

Belangwekkender en nog meer in de reformistische lijn is evenwel de volgende stelling van de kant der vrouw : als er van haar kant geen "feiten zijn gepleegd, die grond opleveren voor verstoting..., kan verstoting alleen plaats hebben met toestemming" van de vrouw. In ieder geval had zij moeten "worden teruggeroepen in de echtelijke woning of althans [moeten] verklaren, in bijzijn van getuigen, dat zij niet wenste terug te keren in de echtelijke woning en ontbinding van het huwelijk van partijen wenste". De verstoting is evenwel door de man "geheel buiten [haar] om geschied en heeft noch in [haar] bijzijn, noch met [haar] voorkennis plaatsgevonden". Zij beschouwt zich dus als nog steeds wettig gehuwd met William A., die derhalve geen nieuw huwelijk kan aangaan. (Immers ook volgens het 'huwelijksbesluit Mohammedanen', kan de man slechts met één vrouw tegelijk wettig gehuwd zijn.)

Hoewel het bij zijn bespreking van het begrip 'sjiqāq' en niet bij 'talāq' is, dat Maulana Muhammad 'Ali stelt: "Het zal wel duidelijk zijn, dat de Heilige Qur'ān de twee partijen ten aanzien van huwelijksontbinding op dezelfde hoogte van volkomen gelijkheid plaatst', 1 beantwoordt het betoog van de vrouw geheel aan deze radikaal-ontraditionele uitspraak.

Verstoting, zo heeft de andere partij - de man, die $n u$ op het punt stond een huwelijk volgens de westerse regels voor de burgerlijke stand te sluiten - geheel traditioneel betoogd, kan plaatsvinden "door enkele wilsuiting van de man". Hij herinnert overigens aan de voorschriften omtrent de iddahtermijn, de wachtperiode, die voor de vrouw geldt. De aanhaling uit de Korān zou slechts "ten dele waar" zijn, en dat deel zou “alleen op partijen van toepassing zijn, als zij ten tijde van de verstoting in hetzelfde huis woonden". De vrouw had ten tijde van de verstoting de echtelijke woning reeds geruime tijd verlaten - het lag dus in de rede, dat de man zijn vrouw op de gewone manier had verstoten. Anderhalf jaar geleden

1 Idem, p. 479. De sjiqãq-procedure is mij persoonlijk alleen uit Indonesië bekend. Zie J. PRINS, Adat en Islamietische plichtenleer in Indonesiē, derde druk, 's-Gravenhage, 1954, p. I3I-r33. 
was zij weggegaan; ze was nooit weer verschenen en had gezwegen, totdat de man weer wilde trouwen. $\mathrm{Hij}$, de man, acht zich volkomen in zijn recht te staan - zoals hij gehandeld heeft, zo is het altijd in Islamietische verhoudingen geoorloofd geweest. Khalief Oemar zelf heeft immers zijn vrouw verstoten, omdat hij, Oemar, niet van partijdigheid beschuldigd wilde worden; niet lang geleden heeft ook de koning van Egypte (ex-koning Faroek) zijn vrouw verstoten, om met Narima te trouwen...

Zonderling is het argument "dat honderden verstotingen plaats hebben in Indonesiē van vrouwen, die in Suriname woonachtig zijn..." - Wellicht betreft dit enige Moslims van Javaanse herkomst, die uit Suriname naar Indonesië teruggekeerd zijn en mogelijk vrouwen in Suriname hebben achtergelaten. ${ }^{1}$ - Als men medewerking van de vrouw nodig heeft, zo vraagt de man, hoe gebeurt dat dan in zulke gevallen? Maar de vrouw is een 'Ahmadijah', en legt de Korān anders uit; hij zelf is, zo verklaart hij, een 'Soenniet'.

De dupliek van de vrouw is een handhaving van haar eerste stellingen; voorts verklaart zij, dat zij niet is weggelopen; zij is weggestuurd; zij wil wel terugkomen, maar de man weigert haar te ontvangen. Nooit heeft zij in deze verstoting berust... en als Khalief Oemar zijn vrouw zonder meer heeft verstoten, heeft hij niet gehandeld volgens de leer van den Islam.

De kantonrechter overwoog tenslotte, dat de verstoting had plaats gehad volgens de leer van den Islam en overeenkomstig het 'huwelijksbesluit Mohammedanen' en hij hief de stuiting van het huwelijk op. Hij constateerde daarbij tevens, dat het 'huwelijksbesluit Mohammedanen' om administratieve redenen voorschrijft, dat van de verstoting aan de door de overheid daartoe aangewezen huwelijksbeambte moet worden kennis gegeven. Aan deze voorwaarde nu was voldaan.

Had de vrouw het recht zich van dit processuële middel der stuiting te bedienen, dat feitelijk behoort tot de voorschriften van westers recht, terwijl hier van een 'Aziatisch' huwelijk sprake was? De rechter achtte, dat het 'huwelijksbesluit Mohammedanen', wat de ontbinding van het huwelijk betreft, slechts "een summiere uiteenzetting over het eenzijdig karakter van de talak" geeft. De vrouw heeft gemeend, zich van een haar toekomend wettelijk recht te moeten bedienen.

Was de rechter zelf onzeker, of hij haar dit subjectieve recht moest toekennen of niet? In elk geval weigerde hij aan de man de gevorderde schadevergoeding toe te kennen, en belastte hij de vrouw alleen met de kosten van het geding. Wij voor ons menen, dat zij dit recht zeer zeker had. Immers, indien het meerdere, te weten het recht tot het aangaan van een huwelijk volgens de regelen van de 'gewone' burgerlijke stand aan Islamietische Surinamers ten volle is toegekend, dient het mindere, namelijk gebruikmaking van rechtsmiddelen, die ter ondersteuning van dit instituut zijn ingesteld, daarbij te zijn inbegrepen. Tenzij anders mocht

1 Deze repatrianten hebben, onder auspiciën van de Jajasan Kembali Tanah Air (= Stichting tot terugkeer naar het vaderland), van ca. 1955 tot $195^{8}$ in een nieuwe vestiging verbleven in de Kabupatèn (= regentschap) Pasaman, provincie Minangkabau, Sumatra. (Mededeling van drs. H. J. HeEREN, Sociologisch Instituut der Rijksuniversiteit, Utrecht). 
zijn bepaald, maar dat is niet het geval. Hoewel ons hier voornamelijk interesseert, dat in dit rechtsgeding de standpunten omtrent het wezen van het Moslimse huwelijk op zo heldere wijze tegenover elkaar zijn gesteld en niet de juridische gang van zaken op zichzelf - menen wij toch te mogen opmerken, dat de kantonrechter niet geheel terecht zijn uitspraak mede heeft gegrond op Juynboll's Handleiding. ${ }^{1}$ Dit is een van de klassieken van de Nederlandse Islāmwetenschap, maar dit boek behandelt de Sjafi'ietische rechtsschool. De traditionele Moslims van Voorindische herkomst in Suriname zijn, als wij het wel hebben, allen 'Hanafieten'. Alleen de Javanen zijn (formeel) 'Sjafi'ieten'.1

De vrouw - het bleek reeds uit het begin van dit verhaal - is in hoger beroep gegaan. Uit de zeer uitvoerige overwegingen van het vonnis van het Hof ${ }^{2}$ wordt hier aangestipt, dat het Hof een huwelijk, gesloten op de voet van het 'huwelijksbesluit Mohammedanen' een kerkelijk huwelijk noemde. Het college sloot zich hierbij aan bij het merkwaardige syncretistische spraakgebruik der Surinaamse samenleving. ${ }^{3}$

Onder andere overwoog het Hof, dat naast het algemeen voorschrift van het burgerlijk wetboek, waarin de wetgever alleen het burgerlijk huwelijk erkent, hij bij artikel I, lid I van het 'huwelijksbesluit Mohammedanen' voor Islamieten en beperkt tot Islamieten óók het 'kerkelijk' huwelijk heeft erkend en geldig verklaard. Zodanig kerkelijk huwelijk heeft dezelfde rechtsgevolgen als het burgerlijk huwelijk, behoudens afwijkingen. En één van die afwijkingen, door dit huwelijksbesluit aangegeven, is, dat ontbinding hetzij door echtscheiding, hetzij door verstoting wordt bewerkstelligd. Van een verstoting moet door de huwelijksbeambte binnen drie dagen, nadat deze onherroepelijk is geworden, aantekening worden gesteld op de akte van inschrijving van het betreffende huwelijk (artikel 22, lid I).

Artikel 22 lid 2 van het huwelijksbesluit schrijft voor, dat uittreksels "uit het register betreffende een verstooting binnen drie dagen, nadat deze onherroepelijk is geworden" moeten worden gezonden aan bepaalde autoriteiten. Het Hof heeft zulk een uittreksel aanvaard als wettig bewijs, dat het huwelijk van William A. en Djamiran O. door verstoting was ontbonden en "sedertdien niet meer als bestaande kan worden aangemerkt". Derhalve was de vrouw onbevoegd tot stuiting van William A's volgende huwelijk en kreeg zij van het Hof ongelijk.

Men moet het vonnis, waarbij, ten gunste van de traditionele leer ten aanzien van de verstoting is beslist, als een juridisch nauwgezet uitgewerkte toepassing van geldend recht, principiëel onberispelijk achten. ${ }^{4}$

1 Dr. Th. W. Juynboll, Handleiding tot de kennis van de Mohammedaansche Wet volgens de leer der Sjafi'itische school, Leiden, 1903.

2 Generale Rol no. 7260, I-6-1956.

3 Naar klassieke Moslimse opvatting is de huwelijkssluiting een zuiver privaatrechtelijke overeenkomst.

$4 \mathrm{Zie}$ de uittreksels uit de overwegingen van het vonnis van de kantonrechter en uit die van het Hof in Surinaamse Jurisprudentie, 1956, no. 15. p. 33 e.v. Het Hof heeft uitvoerig overwogen, in welke verhouding de Aziatische huwelijkswetgeving staat tot de algemene wetgeving op het 
Het was evenwel niet ons naaste doel de rechter te controleren. Wij hebben er ons, gelijk gezegd, voor geïnteresseerd, vanwege de botsing der overtuigingen omtrent wat huwelijksrecht behoort te zijn, die in dit proces tussen de man en zijn vroegere vrouw tot uiting kwam. Een opmerkelijke bijzonderheid is daarbij, dat de man, die zich op het traditionele standpunt heeft gesteld, gereed stond, opnieuw met een Moslimse (althans blijkens haar naam) Hindostaanse te huwen. Maar ditmaal wenste hij (of zij) een 'gewoon' burgerlijke stand-huwelijk te sluiten. Hij is daarmee op zijn beurt een vertegenwoordiger van een tendentie naar verwestersing en naar 'acculturatie' op het stuk van het formele huwelijksrecht.

De vrouw vertegenwoordigt evenwel een standpunt, dat vaak is vertolkt in vertogen van Moslimse vrouwenverenigingen in zulke ver uiteenliggende landen als Indonesië en Egypte, Tunis en Turkije. ${ }^{1}$ Het is of was daar de strijd tegen het eenzijdige verstotingsrecht van de man en het euvel der 'successieve' polygamie. In Turkije is deze strijd formeel beëindigd, doordat de dictator-hervormer Kemal Atatürk in 1926 met één pennestreek het Zwitserse burgerlijk wetboek heeft ingevoerd. Deze radikale maatregel heeft intussen tot belangrijke moeilijkheden gevoerd, die nu, na meer dan dertig jaar, nog niet overwonnen zijn. In Egypte is men er - naar het schijnt - nog niet toe gekomen, het eenzijdige private verstotingsrecht van de man (en evenmin de polygamie) officieël af te schaffen of belangrijk in te perken. Tunis heeft in 1957 het westerse monogame huwelijk ingevoerd. ${ }^{2}$ In Indonesië staat, voorzover ons gebleken is, alle ernstige hervormingsarbeid op dit belangrijke punt der wetgeving al jaren stil.

Djamiran $\mathrm{O}$. heeft natuurlijk het middel van stuiting gehanteerd op instigatie van een Surinaams rechtskundige; zelf zou zij waarschijnlijk nooit op zulk een idee zijn gekomen. Misschien heeft zij van de strijd van Moslimse vrouwenverenigingen vèr weg, in Moslimse kultuurlanden, nooit gehoord. Niettemin zal, naar ik vertrouw, alleen al door de invloed van èn westers recht èn Christelijke opvattingen omtrent de waardigheid van de vrouw, de invloed van haar denkbeelden, reeds vertegenwoordigd door Moslimse reformisten, onweerstaanbaar toenemen. ${ }^{3}$ Het probleem voor de Surinaamse rechters, wat een huwelijk "volgens de leer van den Islam" is en inhoudt, zal vermoedelijk ingewikkelder worden dan het was.

stuk van de burgerlijke stand, om te concluderen, dat het college gehouden is, op dit geschil de regelen van het Huwelijksbesluit Mohammedanen toe te passen.

1 Zie o.a.: J. H. A. Logemann, Moderne receptie van modern recht, Nieuw-Guinea Studiēn 3, I959, p. I66-195. GotThARD JÄschke, Der Islam in der neuen Türkei, Die Welt des Islams (N.S.) $I$, nr. I-2, I95I. G. E. von GrüNEBAUM, Fall and Rise of Islam, Studi orientalistica in onore di Giorgio Levi Della Vida, I. Instituto per l'oriente, nr. 52, Roma, 1956.

2 J. Brugman, De betekenis van het Mohammedaanse recht in het hedendaagse Egypte. Diss. Leiden, I960; Verhand. Kon. Inst. Taal- LandVolkenkunde, 28, 1960 (s.v. polygamie, verstoting).

3 Winkler Prins Encyclopaedie, Suppl. I96o (s.v. Islam, p. 379). 